\title{
Research regarding the common problems of design of the bunkers - A review
}

\author{
Ancuta Alexandra Petre $^{1}$, Mariana Mădălina Stanciu, Dumitru Bogdan Mihalache ${ }^{1}$ and \\ Dragoș Dumitru ${ }^{l}$ \\ ${ }^{1}$ INMA National Institute of Research - Development for Machines and Installations designed to \\ Agriculture and Food Industry, Bucharest
}

\begin{abstract}
Understanding the behavior of granular material in a bunker not only helps to design properly and achieve the correct granular flow, but also needs the engineer to ensure that the bunker is properly designed and conducted to withstand the tasks and demands exercised during its operation. Small and shallow bunkers are commonly used in industry when free space is limited. Shallow bunkers induce the flow of the funnel, which can cause problems such as segregation and agglomeration of the material inside it, which leads to considerable damage to the final product. The design and location of a suitable power supply and an appropriate outlet is still critical and is perceived rather as a science.

The paper presents some innovative solutions related to the design, modeling and construction of solid material storage and unloading bunkers.
\end{abstract}

Keywords: bunkers, seeds, design, problems

\section{Introduction}

Bunkers are used in the food and construction industry for the protection and storage of powdered materials or cereal seeds. Bunkers must be designed in such a way that they are easy to load so that they can be handled by operators. In particular, bunkers also be adequately designed so that granular or semifinal material is easy to unload [1].

The utility of adjustable bunkers is particularly important in the technologies that involve conditioning of wheat seeds or for various equipment used for separating impurities. Technologies that use rotating cylindrical sieves involve the need to create a continuous flow of material for processing, therefore the design of the bunker significantly influences the efficiency of the separation process [2].

The way the bunker is designed affects the flow rate of the powdery material, as granular particles can agglomerate inside it. Also, the way the bunker is designed affects the amount of stored material that can be discharged or the stationary space that reduces the actual storage capacity of the bunker [1].

The flow of gravity-driven granular material has fascinated human beings for millennia, either from hourglass devices for time-tracking or silos for storing grain and other granular products. Currently, industrial processing of granular materials is common and silos are regularly used as storage vessels. The physics of granular flow in general is underdeveloped 
compared to that of traditional Newtonian fluids, such as water, mainly due to the different states of aggregation (solid, liquid, gas type) in which the fluid can be found [3].

Many current studies on granular flow through an opening or slit are based on uniform grains. In almost all experimental or numerical relationships for calculating granular flow, the distribution of granule size or the effect of granule size is ignored. In nature, all phenomena related to granular discharge, such as seed injury due to the tilt of the bunker wall or due to faulty exhaust pipe, these problems occur frequently and the result is the uneven distribution of granules or seeds [4].

From the beginning of the silo storage to contemporary bulk storage of agricultural and industrial materials, bunkers have participated in a prominent function as some of the most common granular material storage structures in the world.

This has led to the need for complete bunker projects, which have also become imperative because of the disastrous malfunctions that have occurred recently [5].

Given every one of the issues identified with the construction and working of the bunkers, it is a fairly huge test to look at the conduct effect of granular material in ssiloss and to propose some creative specialized and factual arrangements on granular stream during filling, stockpiling and dumping measures.

The synthesis attempts to highlight certain clear distinctions between these different situations. The above-mentioned aspects presented in this paper are to be taken into account when designing storage and unloading bunkers.

\section{Materials and methods}

Silo is usually used for storing food seeds in most countries, through its prism cereals are protected from diseases and pests. Silos can be constructed of metal, mud, concrete, and plastic, although no construction has proved to be absolutely satisfactory. The storage time of grain in the silo varies from 6 months to a few years, and storage capacities also vary, depending on the size of the silo [6].

Historically, the development and design of silos has been entirely a practical problem. Their design was conducted by agronomists, farmers or engineers and adapted to their needs. Although a large number of researchers have suggested numerous ingenious geometric shapes, the classic design of storage silos for consumable cereals is based on vertical-cylinder multicell facilities. Within the vertical bunker, the seeds are forced to adapt to the shape of the silo, without considering the natural resting angle of the material.

Some researchers have shown that during the emptying process, large friction forces appear on the walls of the silo, as well as additional dynamic demands. In addition, these considerable bunker design problems lead to the enormous damage of the seed grains caused during the filling and emptying processes, being an additional impediment in their design $[7,8,9]$.

The predominant importance of bunkers and silos for a wide variety of industries is evident by the intense efforts of many researchers to obtain models for the unloading behavior of the particular storage devices $[10,11,12,13]$. The size of the mass flow itself and the difficulties in maintaining reliable and uniform flow behavior are of great interest, as these problems can have major impact consequences.

The sensitivity of metal silos to flame failure is the most important design criteria. The non-symmetric pressure regime that arises during the eccentric discharge of stored granular material frequently results in catastrophic buckling failures, and thin silos are especially vulnerable to this form of failure.(Figure 1). The most common way of damage in an eccentric thin-walled steel silo is the discharge of granular material that occurs through serious damage to the adjacent part [14]. 
Fig. 1. Metal bunker [28]

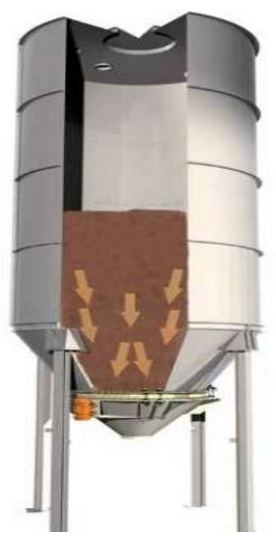

The most basic part of silos pressures is their impact on the planned design that should contain strong material. Since the properties of strong materials shift incredibly, pressing factors can likewise differ significantly, both as far as size, distribuiton and stability. A few conditions lead to eccentric pressing factor tops that can cause genuine harm [15].

The walls of a silo cell are sized for a specific load. It is critical to not use in a bunker, a certain type of granular material that has a specific mass larger than that for which the silo walls are designed. The risk of walls failing is high and this can cause the machine to overturn due to the large amount of material [16].

Initiating the gravitational discharge of granular solids from a storage silo is one of the riskiest operations because it is associated with powerful dynamic effects: rapid pressure pulsations and the transition from active to passive state of stress. Dynamic load pulse can be observed in all types of bunkers with high mass flow, with a filling height greater than the diameter of the bunker.

Pulsating tasks can lead to structural fatigue or even failure when the natural frequencies of silo filling and its structure are aroused by flow impulses [17]. The major differences between the various types of powder flow in bunkers are wall wear, feeding valve, outlet and variations in the discharge time of the granular material shown in Figure 2.
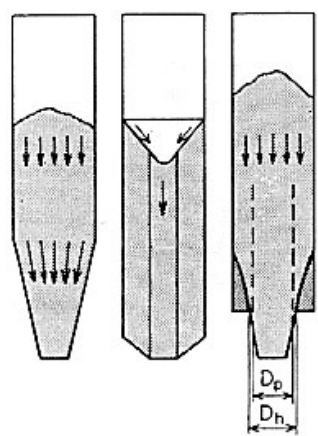

(a)

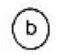

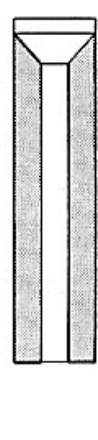

(d)
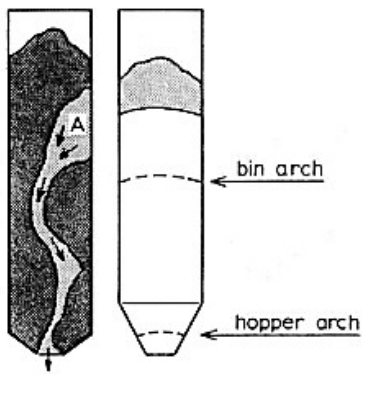

(e)

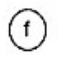

Fig. 2. Types of flow of powders in silos [18]

a. Mass flow b. Funnel flow c. Extended flow rate d. Mass flow of type "pipe" e. Ratholing f. Arching material at unloading

The discharge of the material through the outlet generates mass or funnel flow in the silo, depending on the design of the discharge system. During mass flow, the movement of 
the content material is slow enough and close to the equilibrium state for the inertial forces to be unobservable.

Consequently, the voltage state is similar to the active case, except the kinematic angle of friction of the wall to be used to explain the movement of the silo mass[19].

Different models are used for the design and construction of bunkers, namely: symmetrical cone, asymmetric cone, wedge-shaped bunker with converging walls, chiselshaped bunker, the transition funnel-shaped bunker shown in Figure 3. The shape of the bunker geometry, the shape of the outlet and the supply tank (cylindrical, hemispheric, cone trunk, conical) influence its structure and stability [20].

The pressure of filling and unloading in the silo, which is predicted by the print flows (mass flow and funnel flow), determines the risk of rotation and displacements of the silo wall and other forms of structural deformation. In short, filling and unloading pressures are the most important secondary factors in the design of silos.

Primary cereal processing operations play a particularly important role in the preparation of the final product, as the percentage of seed impurities may be high if harvested improperly. The development cycles of the pollutants of agrarian items likewise vary as per their inclination and the objective they get after collect (preservation, utilization, industrialisation, marketing, planting, and so forth) These activities mean to take out pollutants of any sort, making better capacity conditions, and to decrease the volume of transport and storage.

If all these operations are properly treated, it influences the operation of the bunker at optimum parameters, without further modification [22].

a) Transition bunker

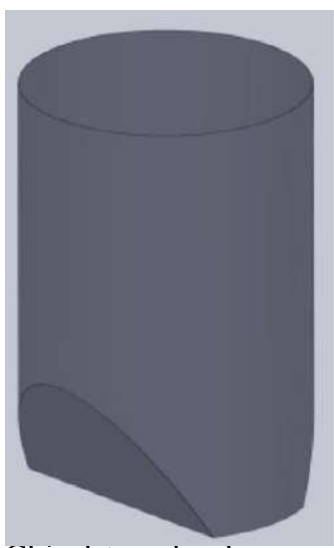

c) Chisel-type bunker b)
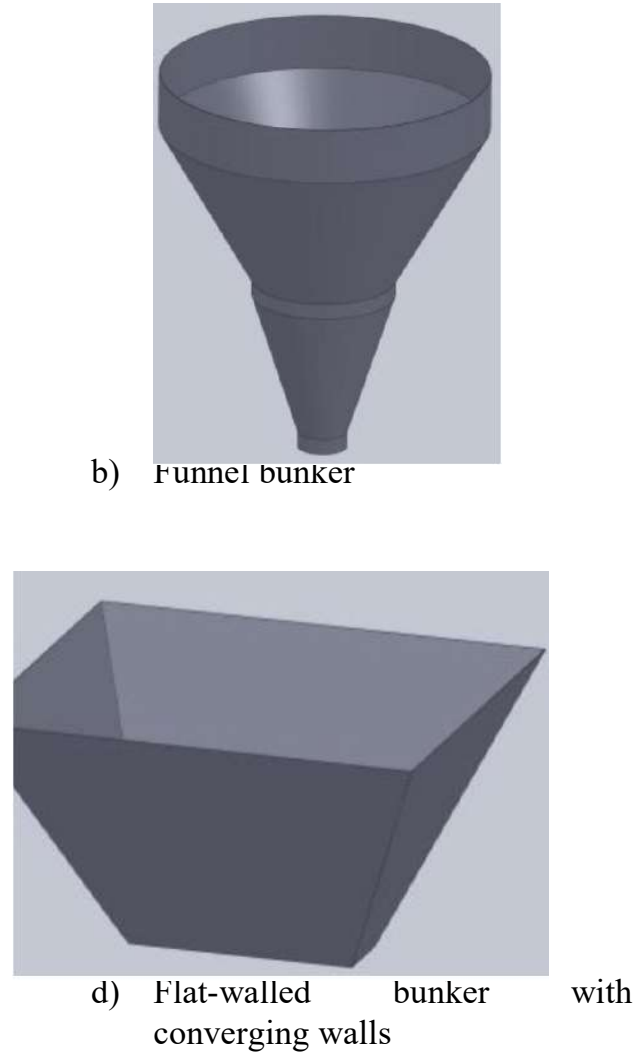


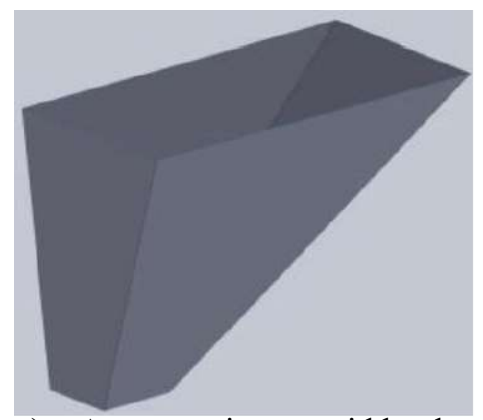

e) Asymmetric pyramid bunker

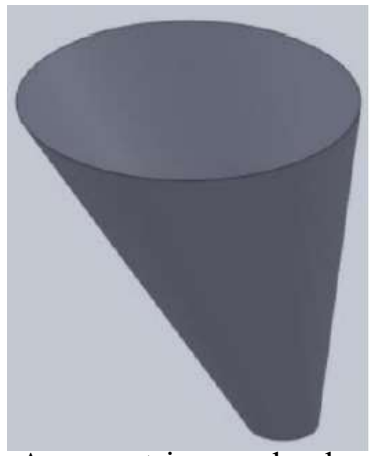

f) Asymmetric cone bunker

Fig. 3. Most used geometric shapes for the design of a bunker [20]

\section{Results and discussions}

The specialists utilized some more established thoughts dependent on the rheology of granular materials and applied them and adjusted them to another sort of bunkers. The recommended geometry depends essentially on the regular resting point of the granular material, just as on the qualities of the stream and circulation of stress inside the storehouse. The new hexagonal geometry is represented in Figure 4 as a typical storage cell, and the cross-section of the cell is divided into two inner sections of the same area using two transverse plates. These plates are parallel to the lower walls of the silo at $35^{\circ}$ in terms of horizontal. The angle has a value close to the natural resting angle of most commercial food cereals. At the bottom, the plates are tilted with the natural resting angle of the cereals, as well as the two internal transverse plates. The seed grains are fed by the feeding vat and the flow of the material is conducted through the outlet positioned at the bottom [23].

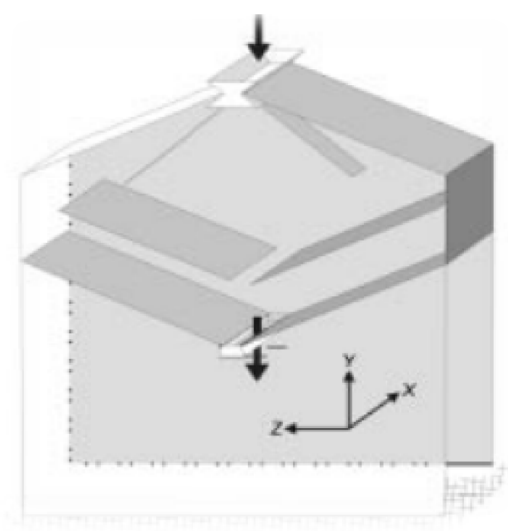

Fig. 4. Hexagonal bunker scheme [23]

Researchers have invented a new macroscopic bunker model that is used to discharge granular material from a lab-scale silo with aluminum walls and adjustable hole size. The silo shaft is $200 \mathrm{~mm}$ in height, $45 \mathrm{~mm}$ in width and $60 \mathrm{~mm}$ in depth. Depending on the size of the hole and the angle of inclination, the funnel has a maximum vertical height of about $100 \mathrm{~mm}$. 
In Figure 5, the angle tilt of the bunker is fixed at $15^{\circ}$, while the size of the hole varies between $5 \mathrm{~mm}, 10 \mathrm{~mm}$ and $15 \mathrm{~mm}$. For the macroscopic model, areas without granular material have been added to the top and bottom of the silo to allow for better particle interaction, ensuring numerical stability [24].

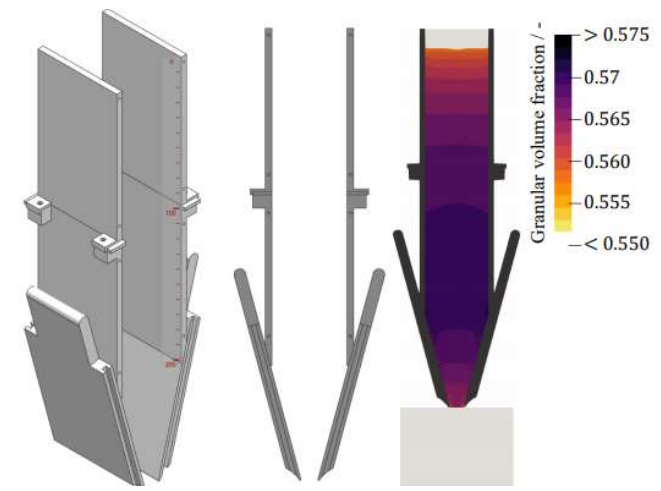

Fig. 5. Macroscopic bunker for laboratory tests [24]

Researchers have thought about the possibility of changing the geometric shape of the bunker that can influence the small mass flow when faced with mass or transition flow, as opposed to the funnel flow. This funnel-type bunker has been used in the past to determine whether a selectively perforated deflector could change the flow regime of the granular material from funnel flow to mass flow. (Figure 6).

While that was possible (a current approach used by the industry is to insert small plates or cones near the funnel outlet, turning it into mass flow), many of the perforated deflectors that produced mass flow had lower mass flow than at the original bunker [25].

Fig. 6. Funnel-shaped bunker [25]

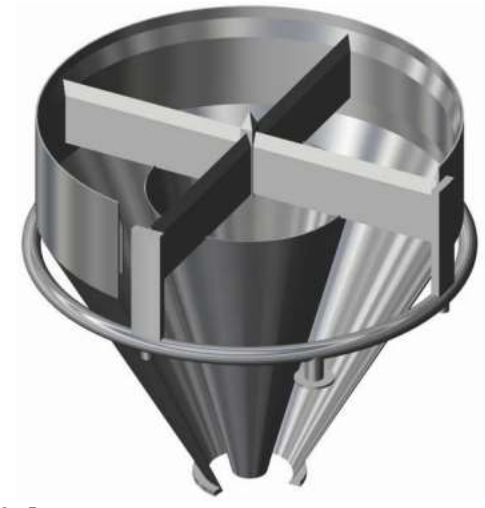

The researchers helped build the current bunker configuration, being presented as a funnel-shaped three-dimensional feather on the wall structure. (Figure 7). Funnel walls are considered rigid because they are treated as fixed limits, resulting in friction of granular materials (including at the bottom).

Friction is assumed to happen when the viscous damping coefficients of the walls are the same as those of the particles. The characteristic size of the socket, D, is assumed to be of the maximum diameter $\mathrm{d}$. The size of the hole affects the density of the material, the propagation of the expansion wave during the flow can cause the material to lock [26]. 
Fig.7. Three-dimensional bunker [26]

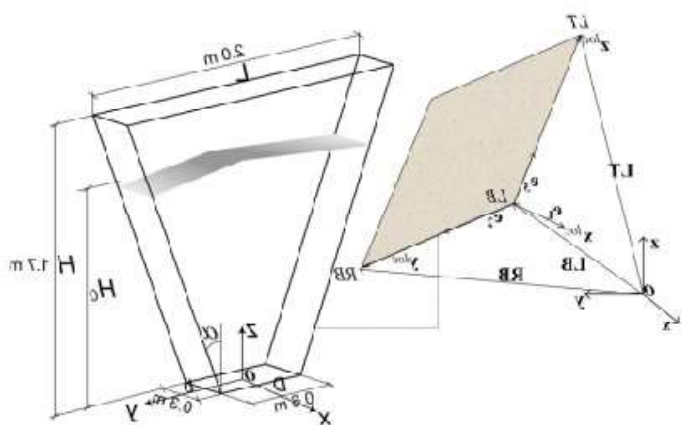

Researchers have faced some current concerns all about drum unloading bunkers due to the use of a large number of parts in the design, large amounts of horsepower and energy consumption, the free space (at rest), but especially its size and size. To overcome these concerns, the vertical discharger shown in Figure 8 has been developed and adapted to solve previous problems.

The powdery material entering the top, i.e. through the power supply valve passes through a rotating cone and subsequently through vertical discharger, resulting in a vertical flow. Adjusting the clearance between the cone and housing is used to allow the flow of material to pass (the intention is to obtain a consistent feed). This "thin cylinder" is gravitationally positioned toward the mixing chamber and the water sprayer [27].

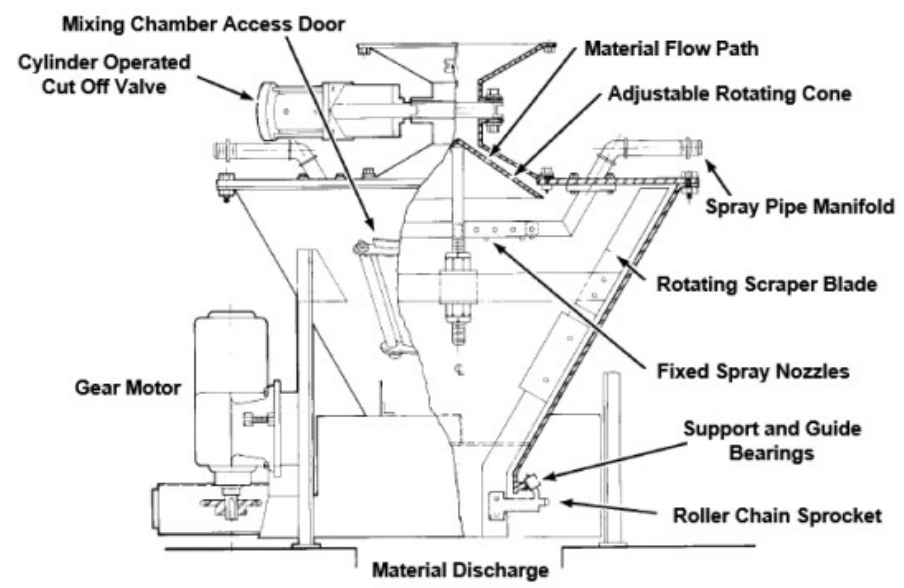

Fig.8. Vertical drum bunker [27]

Researchers have designed precise feeding devices to improve the controlled discharge of materials in the form of powder or granules from silos, bunkers, pneumatic transport systems, or cyclones, with maximum versatility in application.

The RV/RVR rotary valves with circular or square inlet shall consist of a tubular housing of cast iron or stainless steel, a rotor mounted horizontally with a certain number of V-shaped cross-section compartments, an drive unit and a housing cover opposite the end of the unit, presented in figure 9.

This ideal equipment solution has high efficiency of precise filling and measurement in the gravitational supply and pneumatic transport of products in the form of powder and granules [28]. 


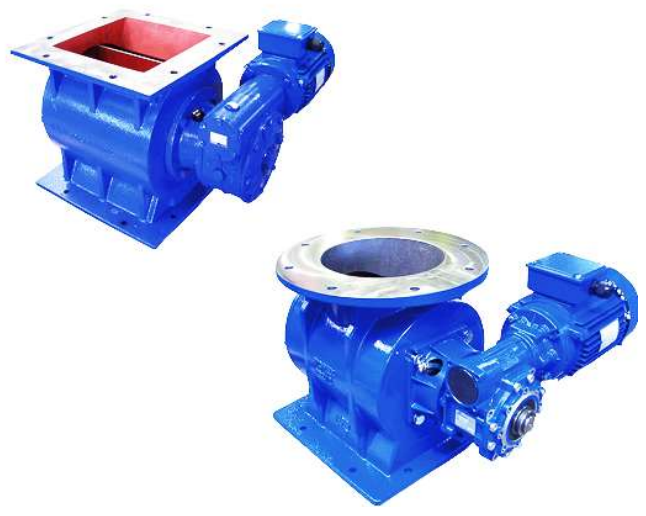

Fig.9. RV/RVR rotary valves [28]

Researchers have implemented a new type of equipment called Hyde TDXZ Vibro which can be attached to any silo for unloading round materials with the help of vibration motion, presented in figure 10. This equipment ensures a uniform and gradual flow through which powdery or granular materials flow through the outlet without being blocked, ensuring a complete discharge without segregation under the vibration of the engine.

When vibrations are applied to a bunker as they discharge, the static bonds that accumulate between the product and the walls of the container, as well as the particle-particle friction that occurs between solid bulk materials such as seeds, dust and sand, are broken, even when moisture is present [29].

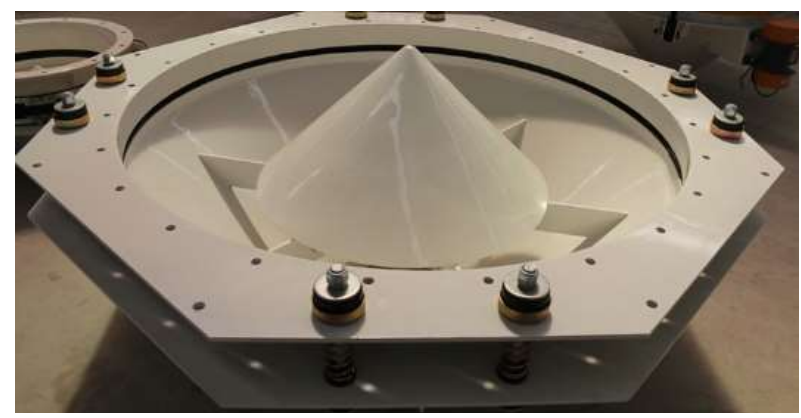

Fig.10. Hyde TDXZ Vibro Discharger [29]

\section{Conclusions}

Internal pressures are substantially higher toward the bottom of the silo, thus flaring becomes plastic and unavoidable. The spill channel or the lack of a flow channel in the actual bunker buildings makes the granular material solid and immobile, which is why this mode is not observed in practice.The presence, type, shape and position of the insertion influences the flow pattern and pressures exerted on the bunker wall.

For structural design, loads and forces occurring inside bunkers or silos must be assessed. Such loads depend heavily on the properties of bulk granular materials. Wall particle friction, stress, ratio and bulk density are important processes that must be determined in advance to avoid the occurrence of the stress interval in that silo.

The position of the stress peak acting on the silo wall is determined by the flow profile (mass flow or funnel flow). In a mass flow silo, the voltage tip is at the transition from the 
cylindrical section to the bunker, whereas in a funnel flow silo, the peak of stress cannot be predicted in advance.

Eccentric flow, which is generated by a poorly built feeder or eccentric discharge, is harmful because it produces in an asymmetrical voltage distribution along the silo wall, which raises the risk of metal wall flaring.

This work was supported by one founding source the NUCLEU Program, carried out with the support of ANCSI, Project PN 5N/07.02.2019 "Integrated management of works in agricultural, vitical and pomicole ferms"

\section{References}

1. G.G. Chase, Course Solids Notes 10, The University of Akron (2010);

2. C. Mircea, F. Nenciu, V. Vlăduț, G. Voicu, D. Cujbescu, I. Găgeanu, I. Voicea, Increasing the performance of cylindrical separators for cereal cleaning, by using an inner helical coil, INMATEH Agric. Engineer., 62, No.3, pp. 249-258, (2020);

3. L. A. Fullard, E. C. P. Breard, C. E. Davies, A. J. R. Godfrey, M. Fukuoka, A. Wade, J. Dufek and G. Lube, The dynamics of granular flow from a silo with two symmetric openings (2019);

4. M. Ostadi, Mechanics of Dry Granular Flow through an Opening, Master of Science in Geotechnical Engineering Department of Civil and Environmental Engineering, University of Alberta, (2019);

5. H.H.N.D. Haggalla, K.I.U. Nanayakkara and H.M.Y.C. Mallikarachchi, Simulating dynamic discharge of infill bulk material stored in cylindrical silos, Society of Structural Engineers, Sri Lanka - Annual sessions, (2019);

6. A. Jacobs, B. Moboladea, N. Bunindrob, D. Sahoob, Y. Rajashekarb, Traditional methods of food grains preservation and storage in Nigeria and India, Annals of Agric. Scien. 64, pp. 196-205, (2019);

7. R. Jackson, J. Rheol. 30, 907, (1986);

8. G. Gudejus, D. Kolymbas and J. Tejchman, Powder Technology 48, 8, (1986);

9. A.V. Potapov, C.S. Campbell, Physics of Fluids 8, 2884, (1996);

10. J. Tomas, Modelling of instationary discharge behaviour of cohesive particulate solids out of bunkers, Chemie-Technik 43(8), pp. 307-309, (1991);

11. D. Barletta, G. Donsì, G. Ferrari, M. Poletto, P. Russo, Solid flow rate prediction in silo discharge of aerated cohesive powders. AIChE J. 53(9), pp. 2240-2253, (2007);

12. R. Baserinia, I.C. Sinka, Mass flow rate of fine and cohesive powders under differential air pressure, Powder Technology 334, 173-182, (2018);

13. W.A. Beverloo, H.A. Leniger, J. van de Velde, The flow of granular solids through orifices, Chem. Engineer. Scien., 15(3-4), pp. 260-269, (1961);

14. A.J. Sadowski, J. M. Rotter, Study of Buckling in Steel Silos under Eccentric Discharge Flows of Stored Solids, J. Eng. Mech. 136:769-776, (2010);

15. J. M. Rotter, Silo and hopper design for strength, Bulk Solids Handling: Equipment Selection and Operation Edited by Don McGlinchey, Blackwell Publishing Ltd. ISBN: 978-1-405-15825-1, (2010);

16. H. Frederiksen, D. Dănuţ, M. Maşinistru, A. Greculescu, Sisteme pentru depozitarea furajelor. Standarde de fermă, Danish Agricultural Advisory Service, (2010); 
17. A.W. Roberts, Review of silo loadings associated with the storage of bulk granular materials, In: CIGR-AgEng International Conference of Agricultural Engineering, Valencia, Spain, pp. 8-12, (2012);

18. R. Zevenhoven, Powder mechanics \& powder flow testing (flow / no flow), Åbo Akademi University, (2018);

19. A.W. Jenike, J.R. Johanson, Bin loads, Proc. Amer. Soc. Civil Eng., J. Structural Div. 94 (ST4):1011-1041, (1968);

20. J. Carsona, D. Craig, Silo design codes: Their limits and inconsistencies, The 7th World Congress on Particle Technology (WCPT7), Publishing Elsevier, (2015);

21. C. Maraveas, Concrete Silos: Failures, Design Issues and Repair/Strengthening Methods, Applied Sciences, MDPI, (2020);

22. C. Brăcăcescu, P. Găgeanu, G. Bunduchi, A. Zaica, Considerations on technical equipment used for cleaning and sorting seed mixtures based on aerodynamic principle, Engineering for rural development, Jelgava, (2018);

23. J. Hernández-Cordero, R. Zenit, E. Geffroy, B. Mena and R. R. Huilgol, Experiments on granular flow in a hexagonal silo: a design that minimizes dynamic stresses, KoreaAustralia Rheology Journal 12, No. 1, pp. 55-67, (2000);

24. R. Hesse1, D. Gilberg, K. Steiner, S. Antonyuk, Modelling of granular flow on microand macroscopic scales with calibration using experimental and numerical setups, Proceedings of the 8th international conference on discrete element methods (DEM8), (2019);

25. M. J. Sandlin, An Experimental and Numerical Study of Granular Hopper Flows, Institute of Technology, Georgia, USA, (2013);

26. I. Sielamowicz, R. Balevičius, Experimental and computational analysis of granular material flow in model silos, IPPT Reports on Fundamental Technological Research, (2013);

27. K. P. Shah, Fundamentals, Troubleshooting \& Maintenance of Ash Handling Plants and Pneumatic Conveying Systems for Bulk Materials, https://practicalmaintenance.net/, (2017);

28. www.wamgroup.com

29. https://maoshengmachinery.en.made-in china.com/product/YXvmroVjhkUa/ChinaFood-Processing-Flour-Mill-Vibro-Sieve-Discharger-Machine.html 